\title{
A Novel Two-Component System PdeK/PdeR Regulates c-di-GMP Turnover and Virulence of Xanthomonas oryzae pv. oryzae
}

\author{
Fenghuan Yang, ${ }^{1}$ Fang Tian, ${ }^{1}$ Lei Sun, ${ }^{1}$ Huamin Chen, ${ }^{1}$ Maosen Wu, ${ }^{1}$ Ching-Hong Yang, ${ }^{2}$ and \\ Chenyang $\mathrm{He}^{1}$
}

${ }^{1}$ State Key Laboratory for Biology of Plant Diseases and Insect Pests, Institute of Plant Protection, Chinese Academy of Agricultural Sciences, Beijing 100193; ${ }^{2}$ Department of Biological Sciences, University of Wisconsin-Milwaukee, 53211, U.S.A.

Submitted 21 January 2012. Accepted 8 June 2012.

\begin{abstract}
Two-component systems (TCS) consisting of histidine kinases (HK) and response regulators (RR) play essential roles in bacteria to sense environmental signals and regulate cell functions. One type of $R R$ is involved in metabolism of cyclic diguanylate (c-di-GMP), a ubiquitous bacterial second messenger. Although genomic studies predicted a large number of them existing in different bacteria, only a few have been studied. In this work, we characterized a novel TCS consisting of PdeK(PXO_01018)/PdeR(PXO_ 01019) from Xanthomonas oryzae pv. oryzae, which causes the bacterial leaf blight of rice. PdeR (containing GGDEF, EAL, and REC domains) was shown to have phosphodiesterase (PDE) activity in vitro by colorimetric assays and high-performance liquid chromatography analysis. The PDE activity of full-length PdeR needs to be triggered by HK PdeK. Deletion of pdeK or pdeR in X. oryzae pv. oryzae PXO99A $^{A}$ had attenuated its virulence on rice. $\Delta p d e K$ and $\Delta p d e R$ secreted less exopolysaccharide than the wild type but there were no changes in terms of motility or extracellular cellulase activity, suggesting the activity of PdeK/PdeR might be specific.
\end{abstract}

Cyclic diguanylate (c-di-GMP), first discovered as an allosteric activator of cellulose synthesis in Gluconacetobacter $x y$ linus (Ross et al. 1987), has emerged as a ubiquitous second messenger in bacterial signaling (Hengge 2009). It is involved in regulation of a variety of functions, including cell differentiation, flagellar motility, biofilm formation, and virulence of pathogens (Aldridge et al. 2003; Cotter and Stibitz 2007; Ryan et al. 2007; Wolfe and Visick 2008). The cellular concentration of c-di-GMP is controlled by the opposite activity of diguanylate cyclase (DGC) and phosphodiesterase (PDE), which are the enzymes to synthesize and degrade c-di-GMP, respectively (Hengge 2009). Genetics and biochemical studies have revealed that GGDEF domains are responsible for the DGC activity, while EAL or HD-GYP domains are associated with PDE activity (Schirmer and Jenal 2009). A large number of GGDEF,

F. Yang, F. Tian, and L. Sun contributed equally to this work.

Corresponding author: C. He; Telephone: (+86) 10 62894147; Fax (+86) 10 62896115; E-mail: cyhe@ caas.net.cn

*The $\boldsymbol{e}$-Xtra logo stands for "electronic extra" and indicates that five supplementary figures and three supplementary tables are published online. Also, Figures 2, 5, and 6 appear in color online.
EAL, and HD-GYP domains have been found in the sequenced bacterial genomes (Seshasayee et al. 2010; Weber et al. 2006). In addition to proteins with only GGDEF or EAL domains, some hybrid proteins containing both domains have also been characterized (Schirmer and Jenal 2009; Seshasayee et al. 2010). Often, only one of them retains the activity to act as either DGC or PDE (Hengge 2009). However, there are several examples where both domains are active enzymes (Ferreira et al. 2008; Tarutina et al. 2006), whereas there are other cases that both domains have lost the conserved residues and do not function as enzymes but, instead, as c-di-GMP effectors (Navarro et al. 2009; Newell et al. 2009).

The majority of these proteins contain accessory domains to facilitate sensing environmental cues and signal transduction to control intracellular c-di-GMP levels (Hengge 2009). These domains include membrane-localization domain HAMP; signal input domains such as PAS, GAF, and blue light sensing (BLUF); and two-component system (TCS) receiver (REC) domain (Gao and Stock 2009; Hengge 2009). A typical TCS contains a signal-sensing histidine kinase (HK) and a response regulator (RR). The signal transduction involves autophosphorylation of $\mathrm{HK}$ at a His residue in the catalytic domain and then phosphoryl group transfer to the Asp residue in REC domain of an RR (Stock et al. 2000). RR trigger responses directly by binding to DNA, RNA, small ligand, or performing enzymatic activities, most of which are related to c-di-GMP metabolism (Gao and Stock 2009).

Xanthomonas oryzae pv. oryzae, the causal agent of bacterial blight disease of rice, has been an important model to study the interaction between plant and bacterium (White and Yang 2009). It has both scientific and economic significance to understand the pathogenesis of $X$. oryzae pv. oryzae. During recent decades, researchers have shown that virulence factors such as exopolysaccharide (EPS), extracellular enzymes, adhesins, and the type III secretion system (T3SS) and its effectors play crucial roles during $X$. oryzae pv. oryzae infection (Das et al. 2009; Ray et al. 2000; Song and Yang 2010; White and Yang 2009). Several TCS components have also been identified as regulators in the signaling network. For example, HrpG, the master regulator for T3SS gene expression, is structurally similar to an RR of the OmpR family (Wengelnik et al. 1996). RaxH/RaxR is required for the activity of AvrXa21 (Burdman et al. 2004). RpfC/RpfG is involved in sensing DSF signal and regulation of virulence factor expression (Andrade et al. 2006; He et al. 2006; Sun et al. 2010). Recently, the genomic studies have predicted that a large number of TCS genes 
exist in X. oryzae (Lee et al. 2005; Qian et al. 2008; Salzberg et al. 2008). However, most of them still require experiments to demonstrate their biological functions.

In this work, we characterized a novel TCS in $X$. oryzae pv. oryzae PXO99 ${ }^{\mathrm{A}}$, consisting of PXO_01018(HK)/PXO_01019 (RR). PXO_01019 is a PDE to hydrolyze second-messenger

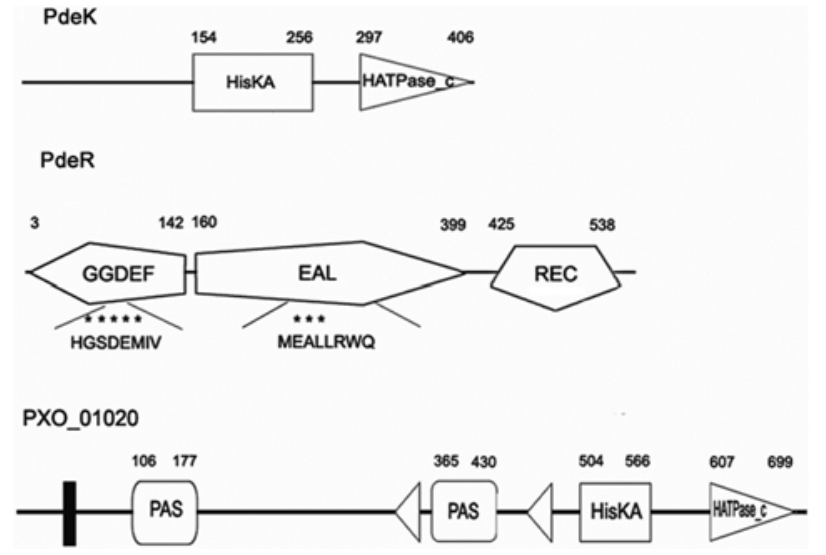

Fig. 1. Schematic representation of the domain structures of PdeK, PdeR, and PXO_01020 from Xanthomonas oryzae pv. oryzae PXO99 ${ }^{\mathrm{A}}$. The numbers represent amino acid residues where the predicted domains start and end, based on the National Center for Biotechnology Information's conserved domain database and simplified modular architecture research tool database. HisKA, histidine kinase A domain; HATPase_c, C-terminal catalytic and ATP binding domain; GGDEF, putative diguanylate cyclase domain; EAL, putative phosphodiesterase domain; REC, receiver domain; PAS, putative PAS signal domain. The black bar and the smaller triangle in PXO_01020 stand for transmembrane (TM) domain and PAC motif, respectively. Asterisks indicate the conserved residues in the GGDEF and EAL domains of PdeR.

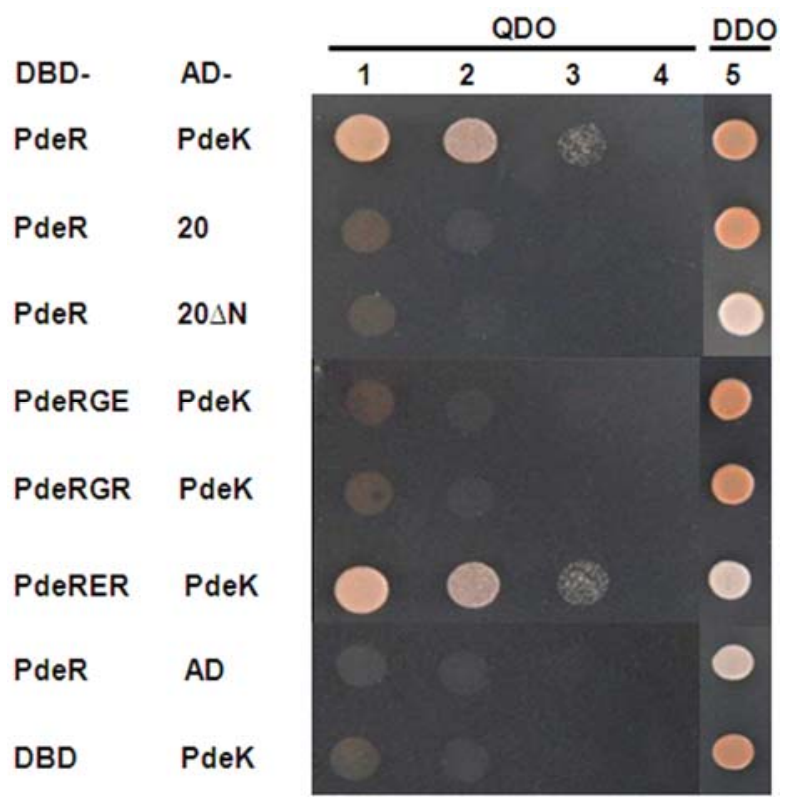

Fig. 2. Interaction between $\mathrm{PdeK}$ and PdeR was detected in the yeast twohybrid (Y2H) assays. Y2HGold yeast strains carrying pGBKT7-derived constructs to express DNA binding domain (DBD) fusions and Y187 yeast strains carrying pGADT7-derived constructs to express activation domain (AD) fusions were mated and selected on double drop-out (DDO) plates for the presence of both plasmids. Only those diploids capable of growth on DDO were further examined on quadruple drop-out (QDO) plates for the interactions between test proteins. Serial dilutions (10-fold) were performed to evaluate the strength of the interactions observed. Abbreviations: 20 and $20 \Delta \mathrm{N}$ are shortened forms for PXO_01020 and PXO_ $01020 \Delta \mathrm{N}$, respectively. Pictures were taken within $48 \mathrm{~h}$ after the cells grew on DDO or QDO plates.
c-di-GMP. Interaction of PXO_01018 with PXO_01019 activated its enzymatic activity. Therefore, we designated $\mathrm{PXO}_{-}$ 01018/PXO_01019 as phosphodiesterase histidine kinase/response regulator (PdeK/PdeR), which is the name we used in the rest of the article. We showed that both PdeK and PdeR were required for the full virulence of $X$. oryzae pv. oryzae.

\section{RESULTS}

Analysis of the c-di-GMP turnover proteins in the genome of PXO99 $\mathrm{A}$.

In all, 26 genes encoding GGDEF, EAL, or HD-GYP domains were found in the genome of $\mathrm{PXO} 99^{\mathrm{A}}$. These genes are scattered around the circular chromosome (Supplementary Fig. S1). Five of them (PXO_00964, PXO_00965, PXO_00967, pdeR, and PXO_01021) have an additional copy due to $212-\mathrm{kb}$ genomic region duplication (Salzberg et al. 2008) (Supplementary Table S1). The domain architectures of them were analyzed by the simplified modular architecture research tool (SMART) online service. Most of them are modular proteins containing multiple domains, including putative signal-sensing motifs, such as PAS, HAMP, and GAF, indicating their involvement in signal transduction. A few of them contain the conserved REC domain and, hence, are predicted as RR in TCS. We were interested in PdeR, which is a putative RR with both GGDEF and EAL domains (Fig. 1). Adjacent to $p d e R$ on the chromosome are two genes encoding putative HK. PdeK contains a conserved HATPase_c for catalytic and ATP binding, and a HisKA domain for phosphotransfer, which is the typical architecture of an HK. In comparison, PXO_01020 contains a transmembrane domain and two PAS domains in addition to the conserved HisKA and HATPase_c domains.

\section{PdeK but not PXO_01020 interacted with PdeR in yeast two-hybrid assays.}

TCS signaling involves specific protein-protein interactions and phosphor group transfer. To determine whether PdeK or PXO_01020 forms a TCS with PdeR, we carried out yeast two-hybrid assays to test the interactions between them using the Matchmaker GAL4-based system. The full lengths of $p d e K$, pdeR, and PXO_01020 gene were cloned into yeast two-hybrid $(\mathrm{Y} 2 \mathrm{H})$ vector pGADT7 to produce proteins fused to the GAL4

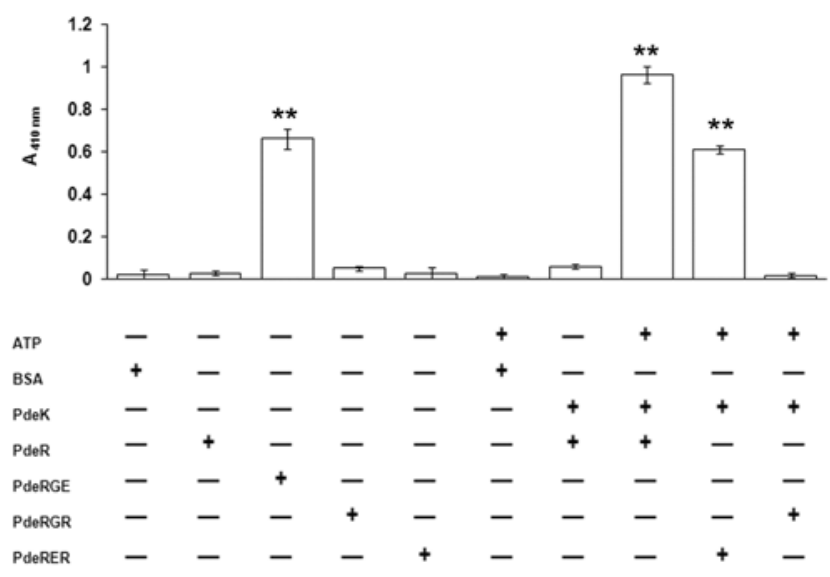

Fig. 3. Phosphodiesterase (PDE) activity of PdeR was detected using the colorimetric assays. A reaction mixture containing different proteins was incubated with the colorless substrate bis (p-nitrophenyl) phosphate at $37^{\circ} \mathrm{C}$ for $2 \mathrm{~h}$. Hydrolysis of colorless bis (p-nitrophenyl) phosphate into yellow p-nitrophenol was detected at $410 \mathrm{~nm}$ by spectrophotometer. The error bar represents standard deviation from three independent experiments; ** indicates significant difference from thebovine serum albumin negative control $(P<0.01$ by Student's $t$ test). 
activation domain (AD). They were also cloned into pGBKT7 to generate proteins fused to the GAL4 DNA binding domain (DBD). Interactions between the fusion proteins were screened for growth on the quadruple drop-out (QDO) media lacking amino acids Trp, Leu, His, and Ade. We found that the yeast diploids containing DBD-PdeR/AD-PdeK grew well (Fig. 2), whereas those containing DBD-PdeR/AD-PXO_01020 did not grow on QDO media (Fig. 2). The same results were obtained after switching the vectors to mate AD-PdeR with DBD-PdeK or DBD-PXO_01020 (data not shown). Because there is a TM domain in the N-terminus of PXO_01020, which might have prevented it from entering into the yeast nucleus and resulted in the negative results, we generated a construct to express the C-terminus of PXO_01020 (PXO_01020C). However, the yeast cells containing DBD-PdeR/AD-PXO_01020C did not grow on QDO plates either (Fig. 2). Therefore, we concluded that PdeK but not PXO_01020 interacted with PdeR. We then tested different fragments of PdeR in the $\mathrm{Y} 2 \mathrm{H}$ assays to find which part directly binds to PdeK. The truncated fusion protein DBD-PdeRER missing the GGDEF domain still interacted with AD-PdeK (Fig. 2). However, the truncated protein DBDPdeRGE or DBD-PdeRGR missing either the REC or EAL domain did not interact with AD-PdeK (Fig. 2). These results suggested that only GGDEF domain is not necessary for interaction with PdeK in $\mathrm{Y} 2 \mathrm{H}$.

\section{PdeR demonstrates PDE but not DGC activity in vitro.}

SMART program analysis indicates that PdeR contains both GGDEF and EAL domains (Fig. 1), which are responsible for synthesis and degradation of c-di-GMP, respectively (Hengge 2009). Thus far, there have been a few proteins with similar domain structures characterized. Often, only one of the domains retains enzymatic activity and the other one plays a regulatory role. To determine whether PdeR is an active PDE or DGC, we decided to purify the protein and test its enzymatic activity in vitro. We cloned the full length of both PdeR and PdeRGE, which has only the GGDEF-EAL domains, into vector pET28, and expressed the His ${ }_{6}$-tagged fusion protein in Escherichia coli BL21 strain. Because we had difficulty in collecting proteins from the soluble fraction, we purified the proteins from the insoluble fraction by denaturation and renaturation methods. The PDE activity of full-length PdeR and PdeRGE was measured using the colorimetric assay (Yi et al. 2010). In this assay, the PDE activity of test protein was indicated by hydrolysis of colorless bis (p-nitrophenyl) phosphate into yellow p-nitrophenol, which can be detected at $410 \mathrm{~nm}$ by spectrophotometer. Incubation of the PdeRGE with bis (p-nitrophenyl) phosphate for $2 \mathrm{~h}$ resulted in production of a significant amount of p-nitrophenol compared with the bovine serum albumin (BSA) control (Fig. 3), suggesting that PdeR has PDE activity. The enzymatic activity was further evaluated by high-pressure liquid chromatography (HPLC) using c-di-GMP as the substrate. PdeRGE was able to hydrolyze c-di-GMP into GMP (Fig. 4). However, either the colorimetric assay or HPLC did not detect the enzymatic activity of the full-length protein of PdeR. These results implied that the REC domain might have inhibited the function of PdeR at the nonphosphorylation state. We also tested whether PdeR had DGC activity using the HPLC assay with GTP as the substrate. No production of c-di-GMP was detected from either the full-length PdeR or PdeRGE (Supplementary Fig. S2). Therefore, we were able to make the conclusion that PdeR demonstrated PDE activity in vitro but no DGC activity was detected under the conditions tested.

\section{PdeK activates the PDE activity of PdeR.}

In the above assay, we did not detect the PDE activity of full-length PdeR but the truncated protein PdeRGE, lacking the REC domain, showed strong PDE activity. In a TCS, the HK often activates the function of RR by phosphorylating its REC domain. Because we showed that HK PdeK interacted
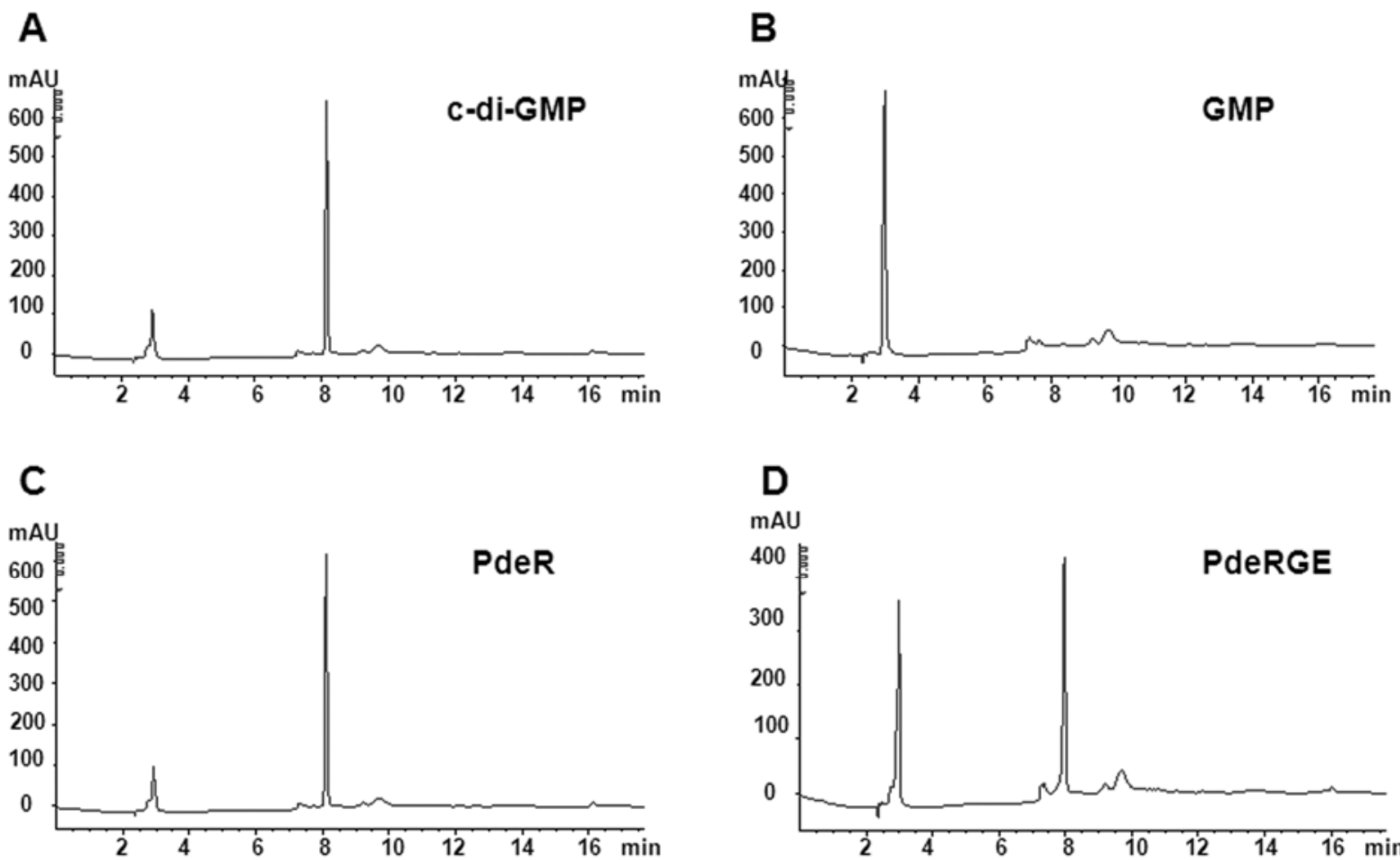

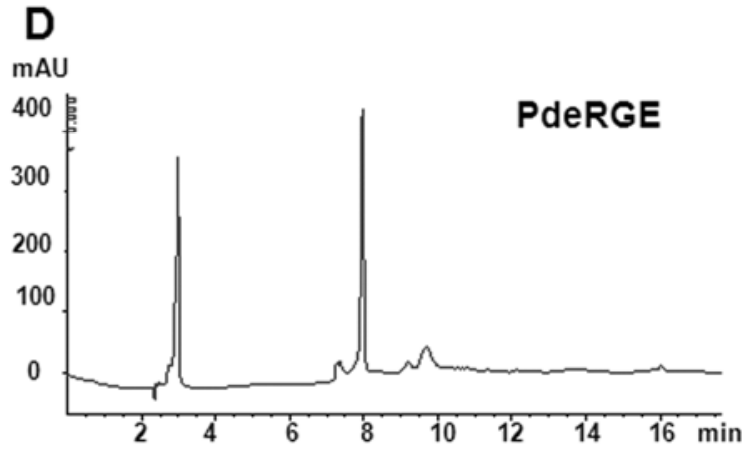

Fig. 4. High-pressure liquid chromatography (HPLC) analysis of the phosphodiesterase (PDE) activity of PdeR. A, Cyclic diguanylate (c-di-GMP) standard B, GMP standard. C and D, Purified full-length PdeR or truncated protein PdeRGE were incubated with 100 mmol of c-di-GMP for 2 h. HPLC was carried out to analyze the products. PdeRGE was able to degrade c-di-GMP into GMP. Degradation of c-di-GMP by full-length PdeR was not detected. The experiment was performed three times using three batches of independently purified proteins. 
with PdeR, we speculated that PdeK might be the cognate HK of PdeR to activate its function. To test the hypothesis, we purified PdeK protein and added it into the mixture with ATP and PdeR protein for the colorimetric assay. In the presence of both PdeK protein and ATP, the full-length PdeR demonstrated strong PDE activity indicated by the high level of p-nitrophenol produced (Fig. 3). Combined with the $\mathrm{Y} 2 \mathrm{H}$ results above, it indicated that PdeK (HK) and PdeR (RR) formed a TCS, and PdeK activated the function of PdeR. To further investigate the role of the GGDEF domain and EAL domain of PdeR, we cloned and purified recombinant proteins PdeRGR and PdeRER, which contain GGDEF-REC and EAL-REC domains of PdeR, respectively. Colorimetric assays were performed to test their enzymatic activities. Without PdeK, both PdeRGR and PdeRER showed no PDE activity (Fig. 3). After adding PdeK and ATP into the reaction mixture, PdeRER but not PdeRGR demonstrated PDE activity (Fig. 3), which is consistent with the notion that the EAL domain is responsible for the PDE activity. In addition, the GGDEF domain might play a positive regulatory role because the activity of PdeRER was approximately $15 \%$ less than that of the full length.

\section{PdeK/PdeR TCS is required}

for the full virulence of $X$. oryzae pv. oryzae in rice.

To determine whether PdeK/PdeR TCS contributes to the virulence of $X$. oryzae pv. oryzae on rice plants, we generated gene deletion mutants $\Delta p d e K$ and $\Delta p d e R$. The virulence of the mutant strains and wild-type PXO99 ${ }^{\mathrm{A}}$ was tested on suscepti-
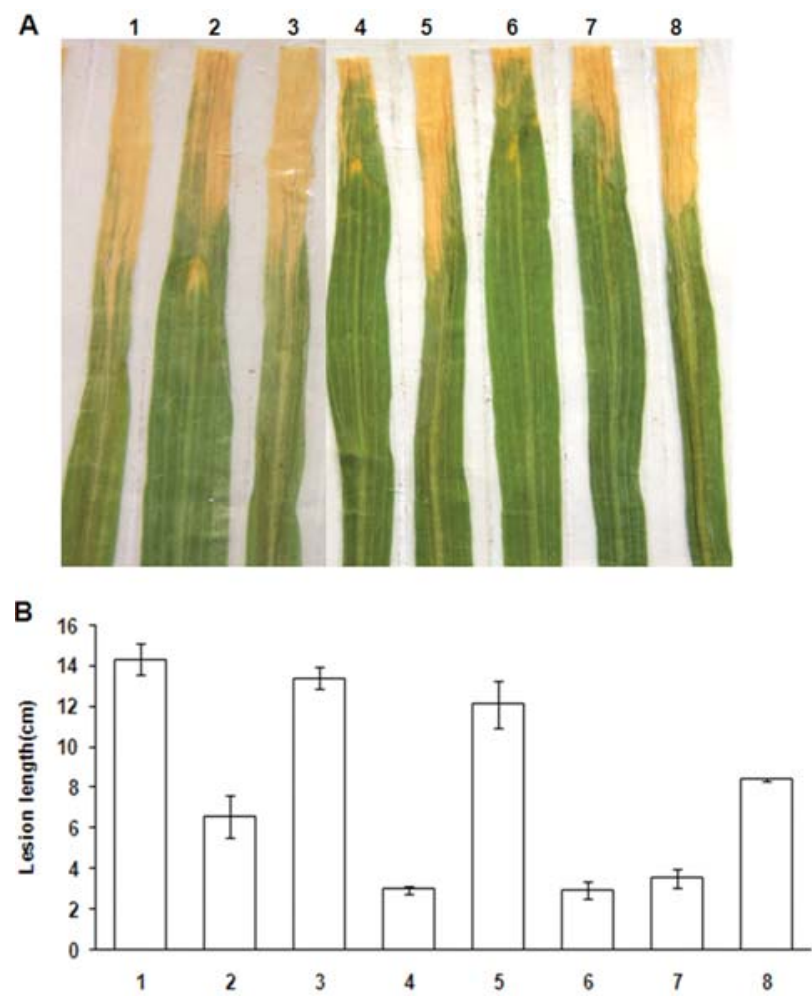

Fig. 5. Virulence of wild-type $\mathrm{PXO} 99^{\mathrm{A}}, \Delta p d e K, \Delta p d e R$, and the complementary strains on susceptible rice Oryza sativa L. subsp. japonica were tested. Bacterial cell suspension at an optical density at $600 \mathrm{~nm}$ of 0.8 was inoculated onto rice leaves by the leaf-clipping method. A, Disease symptoms and $\mathbf{B}$, lesion lengths were scored 14 days postinoculation. Different strains of $\mathrm{PXO} 99^{\mathrm{A}}$ were inoculated: 1 , wild type; $2, \Delta p d e K ; 3, \Delta p d e K$ carrying pHMPdeK for complementation; 4, $\Delta p d e R$; 5-8, complementary strains for $\triangle p d e R$ carrying 5, pHMNPdeR; 6, pHMNPdeRGR; 7, pHMNPdeRER; and 8, pHMNPdeRGE. Values represent means and standard deviation from eight infected leaves in one experiment. The experiment was repeated three times with similar results. ble rice plants. The disease symptoms (Fig. 5A) and the lesion lengths (Fig. 5B) were scored 14 days postinoculation. Compared with the wild type, $\Delta p d e K$ and $\Delta p d e R$ caused much shorter lesions (Fig. 5B). In trans expression of the full-length PdeK and PdeR using the broad-host-vector pHM1 in $\Delta p d e K$ and $\Delta p d e R$, respectively, was able to restore the disease symptoms (Fig. 5A) and lesion lengths (Fig. 5B) to near-wild-type level. We also generated a mutant defective in PXO_01020 and tested its virulence. Compared with the wild type, $\triangle P X O \_01020$ was not impaired in its ability to cause disease on rice leaves (Supplementary Fig. S3). These results indicated that PdeK/ PdeR but not PXO_01020 is required for the full virulence of $X$. oryzae pv. oryzae, which further supported the notion that PdeK but not PXO_01020 forms a TCS with PdeR. To investigate the function of each domain of PdeR in vivo, we used different truncated versions of PdeR in the complementary assay. The fragment PdeRGE was able to restore the phenotype to a certain level, while PdeRGR and PdeRER were less efficient in complementing the disease phenotype (Fig. 5A and B), suggesting that both GGDEF and EAL domains are necessary for the full activity of PdeR in vivo. In addition, expressions of PdeR, PdeRGE, PdeRGR, and PdeRER were confirmed by immunoblotting (data not shown), indicating that the difference observed in the complementation assays was not due to instability of the protein fragments.

\section{PdeK/PdeR TCS regulated EPS production of PXO99A.}

The virulence factors produced by $X$. oryzae pv. oryzae include extracellular enzymes and EPS. Because $\Delta p d e K$ and $\Delta p d e R$ were significantly attenuated in virulence, their ability to produce virulence factors might have been impaired. Experiments to check the secretion of EPS and extracellular enzymes were carried out. Compared with that of the wild type, the colony of $\Delta p d e K$ and $\Delta p d e R$ showed a much drier surface, indicating that the EPS secretion was decreased (Fig. 6). After observing the phenotype from the mutant, the EPS production from wild type and each mutant strain was quantified. The result clearly showed that the amount of EPS secreted from $\Delta p d e K$ and $\Delta p d e R$ was less than $30 \%$ of the wild type (Fig. 6). Complementation of $\Delta p d e K$ and $\Delta p d e R$ with plasmids to express the full-length PdeK and PdeR, respectively, restored EPS production to a near-wild-type level. However, we did not find changes in the secretion of extracellular cellulase or xylanase in the mutants (Supplementary Fig. S4). In several bacterial species, c-di-GMP has been shown to regulate flagellar motility (Wolfe and Visick 2008). To test whether the PdeK/PdeR TCS has similar function, we checked the swimming motility of $\Delta p d e K$ and $\Delta p d e R$. Compared with wild-type

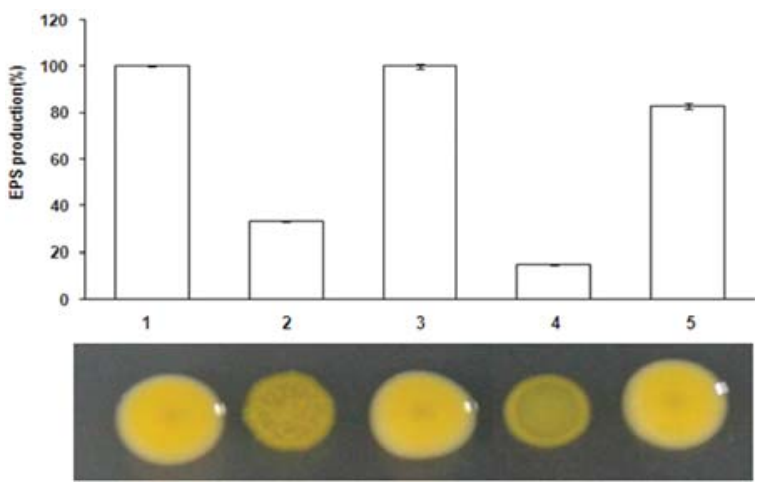

Fig. 6. Secretion of exopolysaccharide (EPS) in $\Delta p d e K$ and $\Delta p d e R$ were reduced. Numbers indicate different strains of PXO99 ${ }^{\mathrm{A}}: 1$, wild type; 2 , $\Delta p d e K ; 3, \Delta p d e K$ carrying pHMPdeK; 4, $\Delta p d e R ; 5 . \Delta p d e R$ carrying pHMNPdeR. Error bars represent standard deviation from three repeats. 
PXO99 ${ }^{\mathrm{A}}$, the swimming sizes of $\Delta p d e K$ or $\Delta p d e R$ showed no difference on the soft agar plates, suggesting that the PdeK/ PdeR TCS is not involved in regulation of motility.

\section{DISCUSSION}

The $X$. oryzae pv. oryzae PXO99A genome encodes 26 genes with putative function involved in metabolism of second-messenger c-di-GMP, 6 of which were predicted to be RR in the bacterial TCS. In this study, we focused on characterizing one of them, PdeR. We showed that PdeR was an active PDE, whose activity required phosphorylation by HK PdeK (Fig. 3). Deletion of $p d e K$ or $p d e R$ in $\mathrm{PXO} 99^{\mathrm{A}}$ attenuated bacterial virulence on rice (Fig. 5). Therefore, PdeK/PdeR is a novel TCS identified in $X$. oryzae pv. oryzae, which is involved in regulation of c-di-GMP turnover and bacterial virulence.

PdeK, PdeR, and PXO_01020 in X. oryzae pv. oryzae PXO99A $^{\mathrm{A}}$ are homologous to XCC1957, XCC1958 (RavR), and XCC1960 (RavS) in X. campestris pv. campestris ATCC33913, with protein sequence similarities of $95.7,94.5$, and $88 \%$, respectively (He et al. 2009). These genes are also conserved in several other Xanthomonas pathovars, including $X$. oryzae $\mathrm{pv}$. oryzicola, $X$. campestris pv. vesicatoria, and $X$. axonopodis pv. citri (BLAST searches). RavS/RavR TCS was recently shown to regulate the virulence phenotypes of $X$. campestris pv. campestris, including secretion of EPS and extracellular protease (He et al. 2009). Mutation of ravS in X. campestris pv. campestris had caused phenotypical changes similar to that of $r a v R$, which was an important piece of evidence to support the idea that RavS/RavR form a TCS (He et al. 2009). Interestingly, we did not detect the interaction between PdeR and PXO_01020 (Fig. 2), which correspond to RavR and RavS, respectively. A mutation of PXO_01020 did not cause reduced virulence, which was the case for $p d e R$ (Fig. 5). Therefore, we conclude that PdeK and PdeR constitute a TCS based on the evidence presented (Figs. 2, 3, and 5). This phenotype is different from their homologs in $X$. campestris pv. campestris and might be due to the genetic divergence between $X$. campestris pv. campestris and $X$. oryzae pv. oryzae during evolution.

The classical model of a TCS signaling involves phosphortransfer from an HK to the Asp residue in the REC domain of an RR, which induces dimerization of the RR and often activates its function (Robinson et al. 2000). Phosphorylationdependent activation has been reported for RR with DGC activity, such as PleD and WspR (Guvener and Harwood 2007; Paul et al. 2007). However, this type of regulation has not been shown in a PDE before. We observed that the N-terminal GGDEF-EAL fragment of PdeR alone showed PDE activity, whereas the full-length protein required the presence of both HK PXO_01018 and ATP (Figs. 3 and 4). These results suggested that the REC domain might have inhibited its function, which was released after phosphorylation. To understand the mechanism underlying this regulation, a crystal structure defining the interaction of the protein $\mathrm{PdeK} / \mathrm{PdeR}$ pair may provide some insight.

PdeR did not demonstrate DGC activity, suggesting that its GGDEF domain (GSDEM) might be degenerate and does not function as an enzyme. This is very similar to PdeA from $\mathrm{Cau}$ lobacter crescentus, which is a GGDEF-EAL protein showing only PDE activity (Christen et al. 2005). The GGDEF domain of PdeA lost enzymatic function but was still able to bind GTP, which allosterically regulated its PDE activity (Christen et al. 2005). In the in vitro experiments to test the PDE activity, the truncated fragment PdeRER showed strong PDE activity comparable with the full-length protein (Fig. 3). However, in the in vivo virulence assay, the plasmid expressing PdeRER was not able to complement the phenotype of $\Delta p d e R$ (Fig. 5). This result suggested that the GGDEF domain was required for the full function of PdeR, especially in vivo. How the GGDEF positively regulates the function of PdeR needs further investigation.

Mutation of $p d e K / p d e R$ in $\mathrm{PXO} 99^{\mathrm{A}}$ impaired the virulence of $X$. oryzae pv. oryzae in rice, probably due to the increase of c-di-GMP concentration in the cell (Fig. 5). Interestingly, both the virulence phenotypes (Fig. 5) and hrp gene expression (Fig. 7B) were more severely affected in $\Delta p d e R$ than in $\Delta p d e K$, implying that other signaling pathways might converge to PdeR. However, whether they indeed exist and how they interact with PdeK/PdeR requires more work in the future. Because the other cellular functions such as motility or extracellular enzyme production were not affected, the effect of PdeK/PdeR seemed to be local and specific. It has been suggested that there are different c-di-GMP pools in the bacterial cell to control a specific set of functions (Hengge 2009; Ryan et al. 2010). In order to exert its effects, c-di-GMP needs to interact with specific effectors. Thus far, several types of c-di-GMP effectors have been identified, including PilZ domains (Amikam and Galperin 2006), transcriptional factors (Hickman and Harwood 2008; Krasteva et al. 2010), degenerate EAL domains (Newell et al. 2009; Qi et al. 2011), and riboswitches (Sudarsan et al. 2008). Different mechanisms are involved in their regulation of specific cellular functions. In accord with Dickeya dadantii, our result showed that c-di-GMP levels regulate the T3SS expression of $X$. oryzae pv. oryzae PXO99 (Yi et al. 2010). However, a direct connection between c-di-GMP effector and T3SS expression has not been identified yet. A CRP-like-protein (Clp), a global transcriptional regulator, has been shown as a c-di-GMP effector in several Xanthomonas spp. (Chin et al. 2010; He et al. 2007; Leduc and Roberts 2009). It will be interesting to find out whether the Clp homolog in $X$. oryzae pv. oryzae or other unknown c-di-GMP effectors are involved in regulation of T3SS expression.
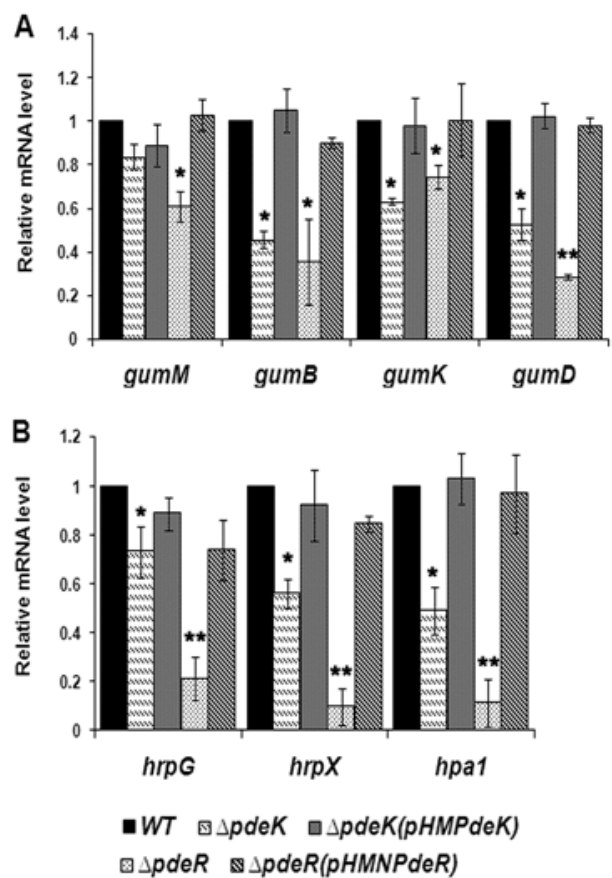

Fig. 7. Quantitative reverse-transcriptase polymerase chain reaction analysis showed that the expression of A, gum genes and B, hrp genes was reduced in $\triangle p d e K$ and $\Delta p d e R$ compared with the wild type (WT). Quantification cycle $(\mathrm{Cq})$ values of target genes were normalized to the reference gene $(g y r B)$. Fold changes of each gene relative to the WT (mathematically designated as 1 here) was calculated using the $2^{-\Delta \Delta \mathrm{Cq}}$ method. Error bars represent standard deviations from four biological repeats; $*$ and $* *$ indicate $P<0.05$ and 0.01 , respectively, by Student's $t$ test. 


\section{MATERIALS AND METHODS}

Bacterial strains and growth conditions.

The bacterial strains and plasmids used in this study are listed in Table 1. E. coli strains were grown in Luria-Bertani medium at $37^{\circ} \mathrm{C}$ (Hanahan 1983). X. oryzae pv. oryzae $\mathrm{PXO} 99^{\mathrm{A}}$ (Hopkins et al. 1992) and derived mutants strains were cultured at $28^{\circ} \mathrm{C}$ on peptone sucrose agar (PSA) medium or M210 liquid medium with appropriate antibiotics. XOM2 medium (Furutanin et al. 2003) was used to induce the expression of T3SS genes. The antibiotics used were ampicillin (Ap), kanamycin $(\mathrm{Km})$, gentamycin $(\mathrm{Gm})$, and spectinomycin $(\mathrm{Sp})$ at concentrations of $100,50,20$, and $50 \mu \mathrm{g} \mathrm{ml}^{-1}$, respectively.

\section{Bioinformatics analysis.}

The genome sequence of X. oryzae pv. oryzae PXO99 ${ }^{\mathrm{A}}$ (GenBank accession number NC_010717.1) was obtained from the
GenBank database. Programs including Expasy and SMART were used to analyze the domain architectures of proteins related to c-di-GMP turnover in the genome PXO99 ${ }^{\mathrm{A}}$.

\section{Cloning of the gene fragments \\ into the middle vector pMD18-T.}

The full lengths of $p d e K, p d e R$, and PXO_01020 were amplified by polymerase chain reaction (PCR) using the primer pairs pdeKPF/pdeKPR, pdeRPF1/pdeRPR1, and 01020PF/01020PR, respectively. A C-terminal fragment of PXO_01020 (504 to 715 amino acids [aa] of PXO_01020) was amplified with 01020PF1/ 01020PR1. The coding regions for PdeRGE (1 to 424 aa of PdeR) and PdeRER (160 to 549 aa of PdeR) were amplified by primer pairs pdeRPF1/pdeRPR2 and pdeRPF3/pdeRPR1, respectively. To obtain a DNA fragment coding for pdeRGR, we first amplified the GGDEF domain (1 to 142 aa of PdeR) and REC domain (425 to 549 aa of PdeR) separately with primers

Table 1. Bacterial strains and plasmids used in this study

\begin{tabular}{|c|c|c|}
\hline Strain or plasmid & Description $^{\text {a }}$ & Reference or source \\
\hline \multicolumn{3}{|l|}{ Escherichia coli } \\
\hline DH5 $\alpha$ & supE44 $\Delta$ lacU169(Ф80lacZ4M15) hsdR17 recA1 endA1 gyrA96 thi-1 relA1 & Hanahan 1983 \\
\hline BL21 & For protein expression & Novagen \\
\hline \multicolumn{3}{|c|}{ Xanthomonas oryzae pv. oryzae } \\
\hline PXO99 & Wild-type strain, Philippine race 6 & Lab collection \\
\hline$\Delta p d e K$ & $p d e K$ gene deletion mutant derived from $\mathrm{PXO} 99^{\mathrm{A}}, \mathrm{Gm}^{\mathrm{r}}$ & This study \\
\hline$\Delta p d e R$ & pdeR gene deletion mutant derived from $\mathrm{PXO} 99^{\mathrm{A}}, \mathrm{Gm}^{\mathrm{r}}$ & This study \\
\hline$\triangle P X O \_01020$ & $P X O \_01020$ gene deletion mutant derived from $\mathrm{PXO99}{ }^{\mathrm{A}}, \mathrm{Gm}^{\mathrm{r}}$ & This study \\
\hline \multicolumn{3}{|c|}{ Saccharomyces cerevisiae } \\
\hline Y2HGold & 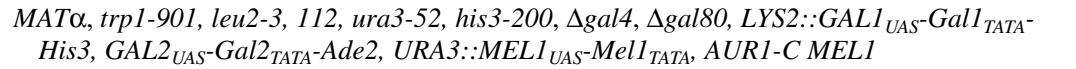 & $\begin{array}{l}\text { Clontech, Mountain } \\
\text { View, CA, U.S.A. }\end{array}$ \\
\hline Y187 & 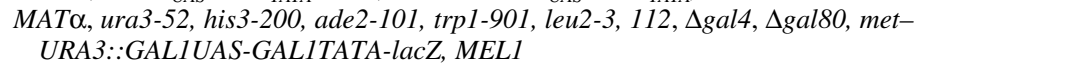 & Clontech \\
\hline \multicolumn{3}{|c|}{ 皮 } \\
\hline pK18mobsacB & Suicidal vector carrying $s a c B$ gene for mutagenesis, $\mathrm{Km}^{\mathrm{r}}$ & Schafer et al. 1994 \\
\hline pMD18-T & Cloning vector, $\mathrm{Ap}^{\mathrm{r}}$ & TaKaRa, Tokyo \\
\hline pHM1 & Broad-host range expression vector, $\mathrm{Sp}^{\mathrm{r}}$ & Hopkins et al. 1992 \\
\hline pET28a & Expression vector to generate a N-terminal $\mathrm{His}_{6}-\mathrm{tag}, \mathrm{Km}^{\mathrm{r}}$ & $\begin{array}{l}\text { Novagen, Madison, } \\
\text { WI, U.S.A. }\end{array}$ \\
\hline pET32a & Expression vector to generate a N-terminal Trx-His ${ }_{6}$-tag, Ap $^{r}$ & Novagen \\
\hline pGADT7 & Yeast-two hybrid vector to create fusion protein containing the GAL4 activation domain, Ap ${ }^{r}$ & Clontech \\
\hline pGBKT7 & Yeast-two hybrid vector to create fusion protein containing GAL4 DNA binding domain, $\mathrm{Km}^{\mathrm{r}}$ & Clontech \\
\hline pKPdeKG & pK18mobsacB derivative carrying a pdeK mutation, $\mathrm{Km}^{\mathrm{r}}, \mathrm{Gm}^{\mathrm{r}}$ & This study \\
\hline pKPdeRG & pK18mobsacB derivative carrying a pdeR mutation, $\mathrm{Km}^{\mathrm{r}}, \mathrm{Gm}^{\mathrm{r}}$ & This study \\
\hline pK01020G & pK18mobsacB derivative carrying a PXO_01020 mutation, $\mathrm{Km}^{\mathrm{r}}, \mathrm{Gm}^{\mathrm{r}}$ & This study \\
\hline pMDPdeK & pMD18-T derivative carrying the full length of $p d e K, \mathrm{Ap}^{\mathrm{r}}$ & This study \\
\hline pMDPdeR & pMD18-T derivative carrying the full length of $p d e R, \mathrm{Ap}^{\mathrm{r}}$ & This study \\
\hline pMD20 & pMD18-T derivative carrying the full length of $P X O \_01020, \mathrm{Ap}^{\mathrm{r}}$ & This study \\
\hline PMD20C & pMD18-T derivative carrying the C-terminal fragment of $P X O \_01020, \mathrm{Ap}^{\mathrm{r}}$ & This study \\
\hline pMDPdeRGE & pMD18-T derivative carrying $p d e R G E$ encoding the GGDEF-EAL domains of PdeR, Ap ${ }^{r}$ & This study \\
\hline pMDPdeRGR & pMD18-T derivative carrying $p d e R G R$ encoding the GGDEF-REC domains of PdeR, Ap ${ }^{r}$ & This study \\
\hline pMDPdeRER & pMD18-T derivative carrying $p d e R E R$ encoding the EAL-REC domains of PdeR, Ap ${ }^{\mathrm{r}}$ & This study \\
\hline pGADPdeK & pGADT7 carrying the full length of $p d e K, \mathrm{Ap}^{\mathrm{r}}$ & This study \\
\hline pGADPdeR & pGADT7 carrying the full length of $p d e R, \mathrm{Ap}^{\mathrm{r}}$ & This study \\
\hline pGAD20 & pGADT7 carrying the full length of $P X O \_01020$, Ap $^{\mathrm{r}}$ & This study \\
\hline pGAD20C & pGADT7 carrying the DNA fragment of $P X O \_01020 C, \mathrm{Ap}^{\mathrm{r}}$ & This study \\
\hline pGBKPdeK & pGBKT7 carrying the full length of $p d e K, \mathrm{Km}^{\mathrm{r}}$ & This study \\
\hline pGBKPdeR & pGBKT7 carrying the full length of $p d e R, \mathrm{Km}^{\mathrm{r}}$ & This study \\
\hline pGBK20 & pGBKT7 carrying the full length of $P X O \_01020, \mathrm{Km}^{\mathrm{r}}$ & This study \\
\hline pGBKPdeRGE & pGBKT7 carrying $p d e R G E, \mathrm{Km}^{\mathrm{r}}$ & This study \\
\hline pGBKPdeRGR & pGBKT7 carrying $p d e R G R, \mathrm{Km}^{\mathrm{r}}$ & This study \\
\hline pGBKPdeRER & pGBKT7 carrying $p d e R E R, \mathrm{Km}^{\mathrm{r}}$ & This study \\
\hline pETPdeK & pET28a carrying the full length of $p d e K, \mathrm{Km}^{\mathrm{r}}$ & This study \\
\hline pETPdeR & pET28a carrying the full length of $p d e R, \mathrm{Km}^{\mathrm{r}}$ & This study \\
\hline pETPdeRGE & pET28a carrying $p d e R G E, \mathrm{Km}^{\mathrm{r}}$ & This study \\
\hline pETPdeRGR & pET32a carrying $p d e R G R, \mathrm{Ap}^{\mathrm{r}}$ & This study \\
\hline pETPdeRER & pET32a carrying $p d e R E R, \mathrm{Ap}^{\mathrm{r}}$ & This study \\
\hline pHMPdeK & pHM1 carrying the full-length of $p d e K, \mathrm{Sp}^{\mathrm{r}}$ & This study \\
\hline pHMNPdeR & pHM1 carrying the full-length of $p d e K$ under the $n p t I I$ promoter, $\mathrm{Sp}^{\mathrm{r}}$ & This study \\
\hline pHMNPdeRGE & pHM1 carrying pdeRGE under the $n p t I I$ promoter, $\mathrm{Sp}^{\mathrm{r}}$ & This study \\
\hline pHMNPdeRGR & pHM1 carrying $p d e R G R$ under the $n p t I I$ promoter, $\mathrm{Sp}^{\mathrm{r}}$ & This study \\
\hline pHMNPdeRER & pHM1 carrying pdeRER under the $n p t I I$ promoter, $\mathrm{Sp}^{\mathrm{r}}$ & This study \\
\hline
\end{tabular}

${ }^{\mathrm{a}} \mathrm{Km}^{\mathrm{r}}, \mathrm{Ap}^{\mathrm{r}}, \mathrm{Gm}^{\mathrm{r}}$, and $\mathrm{Sp}^{\mathrm{r}}$ indicate resistance to kanamycin, ampicillin, gentamycin, and spectinomycin, respectively. 
pdeRPF1/pdeRPR3 and pdeRPF2/pdeRPR1. Then, pdeRPF1/ pdeRPR1 was used to amplify the $p d e R G R$ fragment using the ligation mixture of the previous two fragments as template. The information of these primers was listed in Table 2. The PCR fragments were gel purified and cloned to the middle vector pMD18-T (Takara, Tokyo), resulting in constructs pMDPdeK, pMDPdeR, pMD20, pMD20AN, pMDPdeRGE, pMDPdeRGR, and pMDPdeRER. They were verified by sequencing (Beijing Genomics Institute, Beijing).

\section{Y2H assays.}

$\mathrm{Y} 2 \mathrm{H}$ assays were carried out using the Matchmaker Gold Yeast Two-Hybrid System (Clontech, Mountain View, CA, U.S.A.). The test gene fragment was digested from pMD18-Tderived constructs with corresponding restriction enzymes (New England Biolabs, Beverly, MA, U.S.A.) and ligated into the prey vector pGADT7 or bait vector pGBKT7, resulting in pGADPdeK, pGADPdeR, pGAD20, pGAD20C, pGBKPdeK, pGBKPdeR, pGBK20, pGBKPdeRGE, pGBKPdeRGR, and pGBKPdeRER. pGADPdeK, pGADPdeR, pGAD20, and pGAD20C were transformed into the Saccharomyces cerevisiae Y187 according the manual description, and transformants were selected on a synthetic defined (SD) medium lacking leucine (SD/-Leu). pGBKPdeK, pGBKPdeR, pGBK20, pGBKPdeRGE, pGBKPdeRGR, and pGBKPdeRER were transformed into the $S$. cerevisiae Y2HGold strain and the transformants were selected on SD/-Trp plates. Expressions of fusion proteins in yeast strains were confirmed by Western blotting using anticMyc primary antibodies for pGBKT7 derived constructs and anti-HA primary antibodies (Beijing Protein Institute, Beijing) for pGADT7-derived constructs. Goat anti-mouse immunoglobulin $\mathrm{G}(\mathrm{IgG})$ horseradish peroxidase conjugate secondary antibody (Tiangen Biotech Co., Beijing) was applied to recognize the primary antibodies according to the manual's descriptions. Pairwise yeast mating between haploid cells containing each pGBKT7 and pGADT7 construct was performed in yeastpotato dextrose agar at $28^{\circ} \mathrm{C}$ for $24 \mathrm{~h}$. The obtained diploids were then selected on DDO plates (SD/-Leu/-Trp). Protein interactions were screened on QDO plates (SD/-Leu/-Trp/-Ade/ -His). Diploids were suspended in sterile water and four 10 -fold serial dilutions were performed before $5 \mu \mathrm{l}$ of each dilution was placed on the plates. Growth of the diploid yeast cells on QDO plates in 2 days indicated strong interactions between the test proteins.

\section{Protein expression and purification.}

The coding regions for $p d e K$, pdeR, and $p d e R G E$ were digested from pMDPdeK, pMDPdeR, and pMDPdeRGE, respectively, with EcoRI/HindIII and ligated into expression vector pET28a predigested with the same restriction enzymes, resulting in pETPdeK, pETPdeR, and pETPdeRGE. The $p d e R G R$ and pdeRER fragments were digested from pMDPdeRGR and pMDPdeRER with EcoRI/HindIII and ligated to expression vector $\mathrm{pET} 32 \mathrm{a}$ predigested with the same restriction enzymes, resulting in pETPdeRGR and pETPdeRER. These constructs were transformed into $E$. coli BL21 stains for protein expression. For purification of the proteins, the following protocol was used. Briefly, expression of fusion proteins was induced by addition of isopropyl-thio-galactopyranoside at a final concentration of $0.1 \mathrm{mM}$ and the bacterial cultures were then incubated at $20^{\circ} \mathrm{C} 6 \mathrm{~h}$. The cells were chilled to $4^{\circ} \mathrm{C}$ and collected by centrifugation. The cell pellets were resuspended in phosphate-buffered saline, followed by sonication. The crude cell extracts were centrifuged at $12,000 \mathrm{rpm}$ for $25 \mathrm{~min}$ to get rid of cell debris. The supernatant containing the soluble proteins was collected and mixed with preequilibrated $\mathrm{Ni} 2$ - resin $(\mathrm{GE}$ Healthcare, Piscataway, NJ, U.S.A.) for $2 \mathrm{~h}$ at $4^{\circ} \mathrm{C}$, then placed into a column and extensively washed with buffer containing $20 \mathrm{mM}$ Tris- $\mathrm{HCl}$ (pH 8.0), $350 \mathrm{mM} \mathrm{NaCl}, 0.5 \mathrm{mM}$ EDTA, $10 \%$ glycerol, $5 \mathrm{mM} \mathrm{MgCl}$, and $20 \mathrm{mM}$ imidazole. The proteins were subsequently eluted with buffer containing $300 \mathrm{mM}$ imidazole. The full-length PdeR protein and the PdeRGE fragment were purified from the insoluble fraction by denaturation and renaturation steps. The crude cell extracts were washed with $10 \mathrm{mM}$ Tris- $\mathrm{HCl}$ (pH8.0) twice; then, the cells were collected by centrifugation and denatured with $8 \mathrm{M}$ urea. After the purification process, the renatured proteins were obtained through the gradient dialysis of urea buffer. The purified proteins were analyzed by sodium dodecyl sulfate polyacrylamide gel electrophoresis.

\section{PDE colorimetric assay.}

To test the PDE activity of full-length and different truncated versions of PdeR, $5 \mathrm{mM}$ bis ( $\mathrm{p}$-nitrophenyl) phosphate substrate and the $20 \mu \mathrm{g}$ of purified proteins were incubated at $37^{\circ} \mathrm{C}$ for $1.5 \mathrm{~h}$ in assay buffer $(50 \mathrm{mM}$ Tris- $\mathrm{HCl}$ and $1 \mathrm{mM}$ $\mathrm{MnCl}_{2}, \mathrm{pH}$ 8.5) (Bobrov et al. 2005). The hydrolysis of bis (p-nitrophenyl) phosphate into yellow p-nitrophenyl was detected at $410 \mathrm{~nm}$ by spectrophotometer. BSA was used as a negative control. The experiment was repeated three times using three batches of independently purified proteins.

\section{HPLC analysis.}

HPLC was used to detect the production or degradation of c-di-GMP (Ryjenkov et al. 2005). The putative DGC activity was tested by mixing $25 \mu \mathrm{g}$ of purified proteins with $100 \mu \mathrm{M}$ GTP in the reaction buffer $(75 \mathrm{mM}$ Tris- $\mathrm{HCl}, \mathrm{pH} 7.8 ; 250 \mathrm{mM}$ $\mathrm{NaCl} ; 25 \mathrm{mM} \mathrm{KCl}$; and $10 \mathrm{mM} \mathrm{MgCl}$ ) to a total volume of 1 ml. Samples $(100 \mu \mathrm{l}$ each) were removed at regular intervals and the reaction stopped with $250 \mathrm{mM}$ EDTA. Then, the products were analyzed by HPLC. The putative PDE activity was tested by mixing $20 \mu \mathrm{g}$ of purified proteins with $10 \mu \mathrm{M}$ c-diGMP in the reaction buffer $(50 \mathrm{mM}$ Tris- $\mathrm{HCl}, \mathrm{pH} 7.6 ; 10 \mathrm{mM}$ $\mathrm{MgCl}_{2} ; 10 \mathrm{mM} \mathrm{MnCl}_{2} ; 0.5 \mathrm{mM}$ EDTA; and $50 \mathrm{mM} \mathrm{NaCl}$ ) to a total volume of $1 \mathrm{ml}$. The mixture was incubated at $37^{\circ} \mathrm{C}$ for $1 \mathrm{~h}$. Aliquots (each $100 \mu \mathrm{l}$ ) were withdrawn at the indicated time points and immediately placed in a boiling water bath for $3 \mathrm{~min}$, followed by centrifugation at $12,000 \mathrm{rpm}$ for $2 \mathrm{~min}$. The supernatant was filtered through a $0.22-\mathrm{mm}$ filter and analyzed by HPLC. Reaction samples $(10 \mu \mathrm{l})$ were injected into an extended C-18-T column $(250 \times 4.6 \mathrm{~cm})$ (Agilent) and separated by reversed-phase HPLC at a flow rate of $0.7 \mathrm{ml} \mathrm{min}^{-1}$, and a linear gradient from 0 to $20 \%$ acetonitrile in the buffer $\mathrm{A}$ (10 mm triethylammonium acetate, $\mathrm{pH} \mathrm{5.8)} \mathrm{for} 18 \mathrm{~min}$. The experiment was performed three times using three batches of independently purified proteins.

\section{Construction of mutants and complementation analysis.}

The gene deletion mutants $\triangle p d e K, \Delta p d e R$, and $\triangle P X O \_01020$ derived from $\mathrm{PXO} 99^{\mathrm{A}}$ were constructed by homologous recombination as described previously by using the suicide vector pK18mobSacB (Schafer et al. 1994). The gene fragment of pdeK was amplified using primers pdeKF/R. The left and right arms of $p d e R$ were amplified using primers pdeRLF/LR and pdeRRF/RR, respectively. The left and right arms of $P X O_{-}$ 01020 were amplified using specific primers $01020 \mathrm{LF} / \mathrm{LR}$ and 01020RF/RR, respectively. The DNA fragments were digested with corresponding restriction enzymes and ligated to pK18mobsacB. A Gm resistance gene was then inserted into each gene fragment carried by $\mathrm{pK} 18 \mathrm{mobsacB}$, resulting in plasmids pKPdeKG, pKPdeRG, and pK01020G. The constructs were introduced into PXO99 ${ }^{\mathrm{A}}$ wild-type strain by electroporation. The mutants were screened on PSA plates containing $\mathrm{Gm}$ and $10 \%$ sucrose. The single colonies that were resistant to $\mathrm{Gm}$ but 
sensitive to $\mathrm{Km}$ and a high concentration of sucrose were considered as mutant candidates. Because there are two identical copies of pdeK, pdeR, and PXO_01020 genes on the chromosome, PCR tests were carried out using primers pdeKF/R, pdeRLF/pdeRRR, and 01020LF/01020RR, respectively, to confirm that both copies of the genes were disrupted.

The DNA fragment containing the coding region and the upstream promoter of $p d e K$ was amplified with primers pdeKCF/ $\mathrm{CR}$ and cloned into pHM1 at EcoRI/HindIII sites (Hopkins et al. 1992), generating pHMPdeK. pHMPdeK was electroporated into $\Delta p d e K$ for complementation analysis. The coding sequences for $p d e R$, pdeRGE, pdeRGR, and pdeRER were amplified with primers pdeRCF1/CR1, pdeRCF2/CR1, and pdeRCF1/CR2, using pMDpdeR, pMDpdeRGE, pMDPdeRGR, and pMDPdeRER as template, and were cloned into pHM1 at EcoRI/HindIII sites. The reverse primers pdeRCR1 and pdeRCR2 contain the sequence to generate a C-terminal $\mathrm{His}_{6}$-tag. An EcoRI fragment corresponding to the nptII promoter region was obtained from pML123 (Labes et al. 1990), and inserted in front of the coding region, resulting in constructs $\mathrm{pHMN}$ PdeR, pHMNPdeRGE, pHMNPdeRGR, and pHMNPdeRER. These constructs were electroporated into $\Delta p d e R$ for complementation studies. Expressions of PdeR, PdeRGE, PdeRGR, and PdeRER in the complementary strains were confirmed by Western blotting using anti-His ${ }_{6}$ primary antibodies (Beijing Protein Institute) and goat anti-mouse $\operatorname{IgG}$ horseradish peroxidase conjugate secondary antibody (Tiangen Biotech Co.) according to the manual's descriptions. The chemiluminescence signals were visualized and captured by the CCD camera in a Bio-Rad Gel Documentation system.

\section{Virulence assay.}

The susceptible rice variety Oryza sativa L. subsp. japonica was used in testing the virulence of different PXO99 ${ }^{\mathrm{A}}$ strains. Virulence assays were performed on 6-week-old rice plants under relevant conditions. Wild-type and mutant strains were grown for $72 \mathrm{~h}$ at $28^{\circ} \mathrm{C}$ in $\mathrm{M} 210$ media with appropriate antibiotics. The cells were collected by centrifugation and resuspended in sterile distilled water at a concentration with an optical density at $600 \mathrm{~nm}\left(\mathrm{OD}_{600}\right)$ of 0.8 . Inoculation was carried out using the leaf-clipping method (Ray et al. 2000). Symptoms were recorded by photography and the disease lesion lengths were scored 14 days after inoculation. Eight leaves were inoculated for each strain in each experiment. The experiment was repeated three times.

\section{Motility assay.}

The motility of PXO99 ${ }^{\mathrm{A}}$ strains was tested as previously described (Shen et al. 2001). Bacteria were grown in M210 medium at $28^{\circ} \mathrm{C}$ with shaking at $200 \mathrm{rpm}$, reaching the $\mathrm{OD}_{600}$ of 0.8 . Then, bacteria cells were point inoculated onto the surface of a semisolid plates containing $0.03 \%$ Bacto Peptone, $0.03 \%$ yeast extract, and $0.3 \%$ agar. Pictures were taken after bacterial growth for 4 days. The sizes of the swimming zones were compared between the PXO99 ${ }^{\mathrm{A}}$ wild-type and mutant strains. The experiment was repeated five times.

\section{EPS and extracellular hydrolytic enzymes production assay.}

For analyzing EPS production, the supernatants of bacterial culture $\left(100 \mathrm{ml}, \mathrm{OD}_{600}=3.0\right)$ were collected by centrifugation at $12,000 \mathrm{rpm}$ for $10 \mathrm{~min}$. Two volumes of absolute ethanol were added to the supernatants and the mixtures kept at $-20^{\circ} \mathrm{C}$ for a half-hour. The precipitated EPS molecules were spun down and dried at $55^{\circ} \mathrm{C}$ overnight before determination of dry weight. Production of extracellular cellulase and xylanase activity of PXO99 ${ }^{\mathrm{A}}$ and mutant strains were tested as described (Ray et al. 2000). PSA plates containing $0.5 \%$ carboxymethyl cellulose were used to test cellulase activity. The plates were stained with $0.1 \%$ Congo red for $20 \mathrm{~min}$ and rinsed once with water and twice with $1.0 \mathrm{M} \mathrm{NaCl}$; cellulase-positive colonies would show pale-yellow clear zones against a red background. Xylanase activity was detected by the appearance of white clear zones against a blue background on the PSA plate, which contained $0.2 \%$ RBB-xylan. The experiments were repeated three times.

\section{ACKNOWLEDGMENTS}

We thank J. R. Alfano and W. Hutchins for reviewing the manuscript and helpful discussion, and two anonymous reviewers for suggestions and comments. This work was supported by the grants from the National Basic Research Program (2011CB100701) to C. He and Natural Science Foundation of China (31100947) to F. Tian.

\section{LITERATURE CITED}

Aldridge, P., Paul, R., Goymer, P., Rainey, P., and Jenal, U. 2003. Role of the GGDEF regulator PleD in polar development of Caulobacter crescentus. Mol. Microbiol. 47:1695-1708.

Alfano, J. R., and Collmer, A. 1997. The type III (Hrp) secretion pathway of plant pathogenic bacteria: Trafficking harpins, Avr proteins, and death. J. Bacteriol. 179:5655-5662.

Amikam, D., and Galperin, M. Y. 2006. PilZ domain is part of the bacterial c-di-GMP binding protein. Bioinformatics 22:3-6.

Andrade, M. O., Alegria, M. C., Guzzo, C. R., Docena, C., Rosa, M. C., Ramos, C. H., and Farah, C. S. 2006. The HD-GYP domain of RpfG mediates a direct linkage between the Rpf quorum-sensing pathway and a subset of diguanylate cyclase proteins in the phytopathogen Xanthomonas axonopodis pv. citri. Mol. Microbiol. 62:537-551.

Bobrov, A. G., Kirillina, O., and Perry, R. D. 2005. The phosphodiesterase activity of the HmsP EAL domain is required for negative regulation of biofilm formation in Yersinia pestis. FEMS (Fed. Eur. Microbiol. Soc.) Microbiol. Lett. 247:123-130.

Burdman, S., Shen, Y., Lee, S. W., Xue, Q., and Ronald, P. 2004. RaxH/RaxR: A two-component regulatory system in Xanthomonas oryzae pv. oryzae required for AvrXa21 activity. Mol. Plant-Microbe Interact. 17:602-612.

Chin, K. H., Lee, Y. C., Tu, Z. L., Chen, C. H., Tseng, Y. H., Yang, J. M., Ryan, R. P., McCarthy, Y., Dow, J. M., Wang, A. H., and Chou, S. H. 2010. The cAMP receptor-like protein CLP is a novel c-di-GMP receptor linking cell-cell signaling to virulence gene expression in Xanthomonas campestris. J. Mol. Biol. 396:646-662.

Christen, M., Christen, B., Folcher, M., Schauerte, A., and Jenal, U. 2005 Identification and characterization of a cyclic di-GMP-specific phosphodiesterase and its allosteric control by GTP. J. Biol. Chem. 280:30829-30837.

Cotter, P. A., and Stibitz, S. 2007. c-di-GMP-mediated regulation of virulence and biofilm formation. Curr. Opin. Microbiol. 10:17-23.

Das, A., Rangaraj, N., and Sonti, R. V. 2009. Multiple adhesin-like functions of Xanthomonas oryzae pv. oryzae are involved in promoting leaf attachment, entry, and virulence on rice. Mol. Plant-Microbe Interact. 22:73-85.

Ferreira, R. B., Antunes, L. C., Greenberg, E. P., and McCarter, L. L. 2008. Vibrio parahaemolyticus ScrC modulates cyclic dimeric GMP regulation of gene expression relevant to growth on surfaces. J. Bacteriol. 190:851-860.

Furutanin, A., Tsuge, S., Oku, T., Tsuno, K., Inoue, Y., Ochiai, H., Kaku, H., and Kubo, Y. 2003. Hpal secretion via type III secretion system in Xanthomonas oryzae pv. oryzae. J. Gen. Plant Pathol. 69:271-275.

Gao, R., and Stock, A. M. 2009. Biological insights from structures of two-component proteins. Annu. Rev. Microbiol. 63:133-154.

Guvener, Z. T., and Harwood, C. S. 2007. Subcellular location characteristics of the Pseudomonas aeruginosa GGDEF protein, WspR, indicate that it produces cyclic-di-GMP in response to growth on surfaces. Mol. Microbiol. 66:1459-1473.

Hanahan, D. 1983. Studies on transformation of Escherichia coli with plasmids. J. Mol. Biol. 166:557-580.

He, Y. W., Wang, C., Zhou, L., Song, H., Dow, J. M., and Zhang, L. H. 2006. Dual signaling functions of the hybrid sensor kinase RpfC of Xanthomonas campestris involve either phosphorelay or receiver domain-protein interaction. J. Biol. Chem. 281:33414-33421.

He, Y. W., Ng, A. Y., Xu, M., Lin, K., Wang, L. H., Dong, Y. H., and Zhang, L. H. 2007. Xanthomonas campestris cell-cell communication involves a putative nucleotide receptor protein Clp and a hierarchical 
signalling network. Mol. Microbiol. 64:281-292.

He, Y. W., Boon, C., Zhou, L., and Zhang, L. H. 2009. Co-regulation of Xanthomonas campestris virulence by quorum sensing and a novel twocomponent regulatory system RavS/RavR. Mol. Microbiol. 71:14641476.

Hengge, R. 2009. Principles of c-di-GMP signalling in bacteria. Nature Rev. 7:263-273.

Hickman, J. W., and Harwood, C. S. 2008. Identification of FleQ from Pseudomonas aeruginosa as a c-di-GMP-responsive transcription factor. Mol. Microbiol. 69:376-389.

Hopkins, C. M., White, F. F., Choi, S. H., Guo, A., and Leach, J. E. 1992. Identification of a family of avirulence genes from Xanthomonas oryzae pv. oryzae. Mol. Plant-Microbe Interact. 5:451-459.

Krasteva, P. V., Fong, J. C., Shikuma, N. J., Beyhan, S., Navarro, M. V., Yildiz, F. H., and Sondermann, H. 2010. Vibrio cholerae VpsT regulates matrix production and motility by directly sensing cyclic di-GMP. Science 327:866-868.

Labes, M., Puhler, A., and Simon, R. 1990. A new family of RSF1010-derived expression and lac-fusion broad-host-range vectors for gramnegative bacteria. Gene 89:37-46.

Leduc, J. L., and Roberts, G. P. 2009. Cyclic di-GMP allosterically inhibits the CRP-like protein (Clp) of Xanthomonas axonopodis pv. citri. J. Bacteriol. 191:7121-7122.

Lee, B. M., Park, Y. J., Park, D. S., Kang, H. W., Kim, J. G., Song, E. S., Park, I. C., Yoon, U. H., Hahn, J. H., Koo, B. S., Lee, G. B., Kim, H., Park, H. S., Yoon, K. O., Kim, J. H., Jung, C. H., Koh, N. H., Seo, J. S., and Go, S. J. 2005. The genome sequence of Xanthomonas oryzae pathovar oryzae KACC10331, the bacterial blight pathogen of rice. Nucleic Acids Res. 33:577-586.

Navarro, M. V., De, N., Bae, N., Wang, Q., and Sondermann, H. 2009. Structural analysis of the GGDEF-EAL domain-containing c-di-GMP receptor FimX. Structure 17:1104-1116.

Newell, P. D., Monds, R. D., and O'Toole, G. A. 2009. LapD is a bis$\left(3^{\prime}, 5^{\prime}\right)$-cyclic dimeric GMP-binding protein that regulates surface attachment by Pseudomonas fluorescens Pf0-1. Proc. Natl. Acad. Sci. U.S.A. 106:3461-3466.

Paul, R., Abel, S., Wassmann, P., Beck, A., Heerklotz, H., and Jenal, U. 2007. Activation of the diguanylate cyclase PleD by phosphorylationmediated dimerization. J. Biol. Chem. 282:29170-29177.

Qi, Y., Chuah, M. L., Dong, X., Xie, K., Luo, Z., Tang, K., and Liang, Z. X. 2011. Binding of cyclic diguanylate in the non-catalytic EAL domain of FimX induces a long-range conformational change. J. Biol. Chem. 286:2910-2917

Qian, W., Han, Z. J., and He, C. 2008. Two-component signal transduction systems of Xanthomonas spp.: A lesson from genomics. Mol. Plant-Microbe Interact. 21:151-161.

Ray, S. K., Rajeshwari, R., and Sonti, R. V. 2000. Mutants of Xanthomonas oryzae pv. oryzae deficient in general secretory pathway are virulence deficient and unable to secrete xylanase. Mol. Plant-Microbe Interact. 13:394-401.

Robinson, V. L., Buckler, D. R., and Stock, A. M. 2000. A tale of two components: A novel kinase and a regulatory switch. Nat. Struct. Biol. 7:626-633.

Ross, P., Weinhouse, H., Aloni, Y., Michaeli, D., Weinberger-Ohana, P., Mayer, R., Braun, S., de Vroom, E., van der Marel, G. A., van Boom, J. H., and Benziman, M. 1987. Regulation of cellulose synthesis in Acetobacter xylinum by cyclic diguanylic acid. Nature 325:279-281.

Ryan, R. P., Fouhy, Y., Lucey, J. F., Jiang, B. L., He, Y. Q., Feng, J. X., Tang, J. L., and Dow, J. M. 2007. Cyclic di-GMP signalling in the virulence and environmental adaptation of Xanthomonas campestris. Mol. Microbiol. 63:429-442.

Ryan, R. P., McCarthy, Y., Andrade, M., Farah, C. S., Armitage, J. P., and Dow, J. M. 2010. Cell-cell signal-dependent dynamic interactions be- tween HD-GYP and GGDEF domain proteins mediate virulence in Xanthomonas campestris. Proc. Natl. Acad. Sci. U.S.A. 107:5989-5994. Ryjenkov, D. A., Tarutina, M., Moskvin, O. V., and Gomelsky, M. 2005. Cyclic diguanylate is a ubiquitous signaling molecule in bacteria: Insights into biochemistry of the GGDEF protein domain. J. Bacteriol. 187:1792-1798.

Salzberg, S. L., Sommer, D. D., Schatz, M. C., Phillippy, A. M., Rabinowicz, P. D., Tsuge, S., Furutani, A., Ochiai, H., Delcher, A. L., Kelley, D., Madupu, R., Puiu, D., Radune, D., Shumway, M., Trapnell, C., Aparna, G., Jha, G., Pandey, A., Patil, P. B., Ishihara, H., Meyer, D. F., Szurek, B., Verdier, V., Koebnik, R., Dow, J. M., Ryan, R. P., Hirata, H., Tsuyumu, S., Won Lee, S., Seo, Y. S., Sriariyanum, M., Ronald, P. C., Sonti, R. V., Van Sluys, M. A., Leach, J. E., White, F. F., and Bogdanove, A. J. 2008. Genome sequence and rapid evolution of the rice pathogen Xanthomonas oryzae pv. oryzae PXO99A. BMC Genomics 9:204.

Schafer, A., Tauch, A., Jager, W., Kalinowski, J., Thierbach, G., and Puhler, A. 1994. Small mobilizable multi-purpose cloning vectors derived from the Escherichia coli plasmids pK18 and pK19: Selection of defined deletions in the chromosome of Corynebacterium glutamicum. Gene 145:69-73.

Schirmer, T., and Jenal, U. 2009. Structural and mechanistic determinants of c-di-GMP signalling. Nat. Rev. 7:724-735.

Seshasayee, A. S., Fraser, G. M., and Luscombe, N. M. 2010. Comparative genomics of cyclic-di-GMP signalling in bacteria: Post-translational regulation and catalytic activity. Nucleic Acids Res. 38:5970-5981.

Shen, Y., Chern, M., Silva, F. G., and Ronald, P. 2001. Isolation of a Xanthomonas oryzae pv. oryzae flagellar operon region and molecular characterization of flhF. Mol. Plant-Microbe Interact. 14:204-213.

Song, C., and Yang, B. 2010. Mutagenesis of 18 type III effectors reveals virulence function of XopZ(PXO99) in Xanthomonas oryzae pv. oryzae. Mol. Plant-Microbe Interact. 23:893-902.

Stock, A. M., Robinson, V. L., and Goudreau, P.N. 2000. Two-component signal transduction. Annu. Rev. Biochem. 69:183-215.

Sudarsan, N., Lee, E. R., Weinberg, Z., Moy, R. H., Kim, J. N., Link, K. H., and Breaker, R. R. 2008. Riboswitches in eubacteria sense the second messenger cyclic di-GMP. Science 321:411-413.

Sun, L., Wu, M., Chen, H., and He, C. 2010. Diffusible signal factor production and virulence expression in deltarpfFxoo, deltarpfCxoo and deltarpfGxoo, the gene deletion mutants of DSF/Rpf signaling proteins of Xanthomonas oryzae pv. oryzae. Wei Sheng Wu Xue Bao 50:717723.

Tarutina, M., Ryjenkov, D. A., and Gomelsky, M. 2006. An unorthodox bacteriophytochrome from Rhodobacter sphaeroides involved in turnover of the second messenger c-di-GMP. J. Biol. Chem. 281:3475134758.

Weber, H., Pesavento, C., Possling, A., Tischendorf, G., and Hengge, R. 2006. Cyclic-di-GMP-mediated signalling within the sigma network of Escherichia coli. Mol. Microbiol. 62:1014-1034.

Wengelnik, K., and Bonas, U. 1996. HrpXv, an AraC-type regulator, activates expression of five of the six loci in the hrp cluster of Xanthomonas campestris pv. vesicatoria. J. Bacteriol. 178:3462-3469.

Wengelnik, K., Van den Ackerveken, G., and Bonas, U. 1996. HrpG, a key hrp regulatory protein of Xanthomonas campestris pv. vesicatoria is homologous to two-component response regulators. Mol. Plant-Microbe Interact. 9:704-712.

White, F. F., and Yang, B. 2009. Host and pathogen factors controlling the rice-Xanthomonas oryzae interaction. Plant Physiol. 150:1677-1686.

Wolfe, A. J., and Visick, K. L. 2008. Get the message out: Cyclic-Di-GMP regulates multiple levels of flagellum-based motility. J. Bacteriol. 190:463-475

Yi, X., Yamazaki, A., Biddle, E., Zeng, Q., and Yang, C. H. 2010. Genetic analysis of two phosphodiesterases reveals cyclic diguanylate regulation of virulence factors in Dickeya dadantii. Mol. Microbiol. 77:787-800. 